Arq. Bras. Med. Vet. Zootec., v.67, n.1, p.71-79, 2015

\title{
Efeito da suplementação com vitamina E sobre os metabolismos oxidativo e cardíaco em equinos submetidos a exercício de alta intensidade
}

\author{
[Effect of vitamin E on oxidative and cardiac metabolism in horses submitted \\ to high intensity exercise] \\ L.A. Yonezawa ${ }^{1 *}$, T.S. Barbosa ${ }^{2}$, M.J. Watanabe ${ }^{2}$, C.L. Marinho ${ }^{2}$, \\ J.L. Knaut ${ }^{2}$, A. Kohayagawa ${ }^{2}$ \\ ${ }^{1}$ Centro de Ciências Agroveterinárias - Universidade do Estado de Santa Catarina - UDESC - Lages, SC \\ ${ }^{2}$ Faculdade de Medicina Veterinária e Zootecnia - Universidade Estadual Paulista - Unesp - Botucatu, SP

\section{RESUMO} \\ A suplementação antioxidante visa prevenir os danos oxidativos induzidos pelo exercício físico em \\ diversos tecidos, como o miocárdio. Nesse contexto, este estudo objetivou avaliar os marcadores \\ cardíacos e a lipoperoxidação em equinos no teste de exercício de rápida aceleração e curta duração \\ (TRA), em esteira de alta velocidade, antes e após a suplementação com vitamina E. Para tanto, foram \\ utilizados 10 equinos sem treinamento, que realizaram o primeiro TRA (TRA1) com carga de trabalho \\ fundamentada no consumo máximo de oxigênio individual $\left(\mathrm{VO}_{2 \max }\right)$ e que induziu a concentração de \\ lactato maior que $4 \mathrm{mmol} / \mathrm{L}$, sendo considerado predominantemente anaeróbico. Em seguida, os equinos \\ receberam vitamina $\mathrm{E}$ (dl-alfa-tocoferol) na dose de 1.000UI/dia, por via oral, durante 52 dias, e, \\ posteriormente, realizaram um segundo TRA (TRA2) com o mesmo protocolo de TRA1. As amostras de \\ sangue foram colhidas nos momentos antes do exercício, imediatamente após o término do teste e em $1 \mathrm{~h}$, \\ $3 \mathrm{~h}, 6 \mathrm{~h}, 12 \mathrm{~h}$ e $24 \mathrm{~h}$ subsequentes. Determinou-se o malondialdeído (MDA) plasmático como índice de \\ lipoperoxidação, e as concentrações séricas de troponina I cardíaca (cTnI), isoenzima MB da \\ creatinoquinase (CK-MB) e mioglobina, como marcadores cardíacos. Como efeito do exercício, \\ observou-se aumento discreto de MDA, de cTnI e de CK-MB, sendo significativo apenas para CK-MB. A \\ suplementação foi capaz de amenizar a produção das espécies reativas de oxigênio, evidenciada pela \\ menor concentração de MDA em TRA2, em 24h, além de causar um efeito protetor no miocárdio, devido \\ ao menor valor de cTnI em $6 \mathrm{~h}$ no TRA2 em relação ao TRA1. Não houve grandes alterações na \\ concentração de mioglobina. Concluiu-se que o exercício de alta intensidade promoveu estresse no \\ miocárdio nos equinos avaliados, bem como houve efeito benéfico da vitamina $\mathrm{E}$ na proteção miocárdica \\ e sobre a lipoperoxidação.
}

Palavras-chave: antioxidante, fisiologia do exercício, marcadores cardíacos, malondialdeído, cavalo

\begin{abstract}
Antioxidant supplementation aims to prevent oxidative damage induced by physical exercise in several tissues, including myocardium. This study aimed to assess cardiac and lipid peroxidation markers of horses submitted to a high intensity and short duration exercise test (TRA) on a high speed treadmill, before and after vitamin E supplementation. Ten untrained horses performed the first TRA test (TRA1), with workload based on maximal oxygen uptake $\left(V O_{2 \max }\right)$, which induced a blood lactate higher than 4mmol/L, i.e. predominantly anaerobic exercise test. After TRA1, the horses were supplemented with oral vitamin $E$ (dl-alpha-tocopherol) at a daily dose of 1,000IU for 52 days. Then they performed the second test (TRA2) with the same protocol of TRA1. Blood samples were collected before exercise, immediately after and at $1 \mathrm{~h}, 3 \mathrm{~h}, 6 \mathrm{~h}, 12 \mathrm{~h}$ and $24 \mathrm{~h}$ after the end of test. Plasma malondialdehyde (MDA), as lipid peroxidation index, and serum cardiac troponin I (cTnI), creatine kinase isoenzyme MB (CK-MB) and myoglobin, as cardiac markers, were determined. There was a slight increase in MDA, cTnI and CK-MB
\end{abstract}

Recebido em 10 de julho de 2013

Aceito em 30 de julho de 2014

E-mail: leticia@gmail.com 
levels caused by the exercise, but statistically significant only for $C K-M B$ levels. Vitamin $E$ was effective on scavenging reactive oxygen species, as evidenced by lower MDA level after supplementation (TRA2) at $24 \mathrm{~h}$. Also, vitamin E caused myocardial protection showed by lower cTnI concentration at $6 \mathrm{~h}$ in TRA2 when compared to TRA1. There were no changes on myoglobin levels. In conclusion, high intensity exercise induced myocardial stress in horses and we also verified the beneficial effect of vitamin $E$ on myocardial protection and lipid peroxidation.

Keywords: antioxidant, exercise physiology, cardiac markers, malondialdehyde, horse

\section{INTRODUÇÃO}

O fornecimento de energia no organismo é normalmente acompanhado por reações de oxidorredução para a manutenção da integridade e função das células. Grande parte do oxigênio consumido é transformada em dióxido de carbono e água. Contudo, 1 a 5\% são reduzidos a metabólitos reativos, conhecidos como espécies reativas de oxigênio (ERO), que podem causar danos celulares (Deaton e Martin, 2003).

No exercício, há elevação da demanda de oxigênio em relação ao estado de repouso e, com aumento do consumo de oxigênio pela mitocôndria e do fluxo de elétrons através da cadeia respiratória, ocorre maior produção de ERO. Em exercícios anaeróbicos, o organismo utiliza principalmente os fosfatos de alta energia estocados nas células e o sistema glicolítico lático como vias metabólicas para ressíntese de ATP. Adicionalmente, a produção de ERO também ocorre por outros mecanismos, como a ativação da xantina oxidase, devido ao fenômeno da isquemia-reperfusão, a explosão respiratória dos leucócitos, devido a processos inflamatórios, e a oxidação de catecolaminas e de ácido lático (Kostaropoulos et al., 2006). Quando as defesas antioxidantes das células e dos fluidos extracelulares não são capazes de neutralizar as ERO, institui-se o estresse oxidativo, do qual pode ocorrer lipoperoxidação das membranas celulares e lesão tecidual (Yonezawa et al., 2010a).

Embora as defesas antioxidantes endógenas sejam efetivas, os componentes celulares não estão totalmente protegidos, sendo indispensável a obtenção de antioxidantes na dieta para uma defesa apropriada contra processos oxidativos e manutenção da saúde (Cerqueira et al., 2007). Considerando o efeito deletério da produção excessiva de ERO e a evidência de que o exercício induz o estresse oxidativo em equinos, a suplementação com antioxidantes objetiva restabelecer ou manter o equilíbrio oxidante/antioxidante e parece ser uma perspectiva promissora para o bem-estar animal e prevenção de lesões (Yonezawa et al., 2010a).

A vitamina E (dl-alfa-tocoferol) é um antioxidante amplamente estudado para prevenção de lesões oxidativas (Williams e Carlucci, 2006; Yonezawa et al., 2010a) e parece assumir um papel determinante na proteção do coração contra situações deletérias decorrentes do exercício agudo. Como o músculo cardíaco apresenta um alto metabolismo aeróbico, há elevada taxa de metabolismo oxidativo geralmente associada à produção acrescida de ERO. Contudo, no coração, a capacidade antioxidante parece ser limitada, tornando-o susceptível à lesão tecidual por estresse oxidativo após um período de exercício agudo (Ascensão et al., 2003; Yonezawa et al., 2010a).

Segundo Durando et al. (2007), na espécie equina é difícil a avaliação de disfunção miocárdica que ocorre durante o exercício. Embora os exames eletro e ecocardiográficos sejam excelentes ferramentas diagnósticas para arritmias e função ventricular, requerem equipamentos sofisticados e conhecimento das técnicas, que nem sempre estão disponíveis. Desse modo, seria muito conveniente um teste diagnóstico que pudesse complementar a avaliação dos efeitos do exercício na função cardíaca em cavalos, uma vez que as alterações cardíacas são referidas como importante causa de queda de desempenho em equinos (Yonezawa $e t$ al., 2010a; Yonezawa et al., 2010b).

Tradicionalmente, a concentração sérica da isoenzima $\mathrm{MB}$ da creatinoquinase (CK-MB) é mensurada com limitações baseadas na meiavida curta e reatividade cruzada com o músculo esquelético (Phillips et al., 2003). Reimer et al. (1992) relataram aumento da concentração da CK-MB sérica como método de diagnosticar 
injúria miocárdica em equinos com taquicardia ventricular. Em humanos, utiliza-se também a mensuração da mioglobina para avaliação de doenças miocárdicas, mas não apresenta cardioespecificidade, devendo ser acompanhada dos demais marcadores cardíacos para suprir essa limitação (Godoy et al., 1998).

A troponina I cardíaca (cTnI) foi descrita como um marcador cardíaco altamente específico e sensível para injúria miocárdica em equinos. Muitos trabalhos descrevem que a cTnI do miocárdio equino apresenta alta reatividade com os kits comerciais de imunoensaios humanos de cTnI, podendo ser utilizada como biomarcador de lesão de cardiomiócitos (Phillips et al., 2003; Durando et al., 2007; Nostell e Häggström, 2008; Yonezawa et al., 2010b).

Embora haja na literatura muitos trabalhos que relatam a elevação da concentração sérica de troponina após atividade física, não há um consenso sobre a prevalência, os mecanismos e o significado clínico da liberação de troponina induzida pelo exercício (Shave et al., 2010). Desse modo, o presente estudo objetivou a determinação dos marcadores cardíacos e de lipoperoxidação em equinos submetidos a exercício de rápida aceleração e curta duração, considerado de alta intensidade, nas condições de pré e pós-suplementação com vitamina $\mathrm{E}$.

\section{MATERIAL E MÉTODOS}

O presente estudo foi aprovado pela Câmara de Ética em Experimentação Animal (protocolo n ${ }^{\circ}$ 188/2007-CEEA) da Faculdade de Medicina Veterinária e Zootecnia da Universidade Estadual Paulista, Campus de Botucatu.

Dez equinos foram utilizados, sendo cinco da raça Puro Sangue Árabe e cinco da raça Crioula, sem treinamento físico por mais de um ano, com idade variando de oito a 10 anos, peso médio de
$372,1 \pm 32,9 \mathrm{~kg}$, clinicamente hígidos. Os animais foram mantidos em piquetes do Hospital Veterinário da Faculdade de Medicina Veterinária e Zootecnia (FMVZ) da Universidade Estadual Paulista (Unesp), Campus de Botucatu, sob as mesmas condições de manejo alimentar e sanitário. O manejo nutricional consistiu em alimentação à base de feno de capim "coast-cross" (Cynodon dactylon), ração comercial para equinos (Royal Horse Sport, Socil, Brasil), suplemento mineral (Equifós, Matsuda, Brasil) e água ad libitum.

Os equinos foram submetidos a um teste padrão de exercício progressivo em esteira de alta velocidade (Mustang 2200 AG, Kagra, Suíça), inclinada a $6 \%$, na qual a velocidade foi elevada gradualmente, conforme o protocolo de exercício proposto por Watanabe et al. (2009). Utilizou-se a máscara de análise de trocas gasosas e dados ventilatórios (Metavet, Cortex, Alemanha) para se extrair a carga de trabalho para cada equino, com base no consumo máximo de oxigênio $\left(\mathrm{VO}_{2 \mathrm{max}}\right)$ (Watanabe et al., 2009), sendo o valor médio dos animais de $110,4 \pm 20,4 \mathrm{~mL} / \mathrm{kg} / \mathrm{min}$.

Após sete dias do teste progressivo, os equinos foram submetidos ao teste de rápida aceleração e curta duração (TRA) 1. O teste, considerado um exercício predominantemente anaeróbico (concentração de lactato maior que $4 \mathrm{mmol} / \mathrm{L}$ ), consistiu, em esteira inclinada a $6 \%$, em um período de aquecimento de $5 \mathrm{~min}$ com a carga de trabalho de $50 \%$ do $\mathrm{VO}_{2 \max }$ (velocidade média de $3,7 \pm 0,9 \mathrm{~m} / \mathrm{s}$ ), seguido por mais $5 \mathrm{~min}$ à velocidade de $1,5 \mathrm{~m} / \mathrm{s}$. Assim, a manta da esteira foi acelerada tão rapidamente quanto possível para a velocidade individual calculada, para alcançar a carga de trabalho de $105 \%$ do $\mathrm{VO}_{2 \max }$ (velocidade média de 9,2 $\pm 2,1 \mathrm{~m} / \mathrm{s}$ ), com duração de 90s. Logo após, houve um período de desaquecimento, consistindo em $5 \mathrm{~min}$ à velocidade de $3,0 \mathrm{~m} / \mathrm{s}$, com a esteira na posição horizontal (Prince et al., 2002) (Fig. 1).

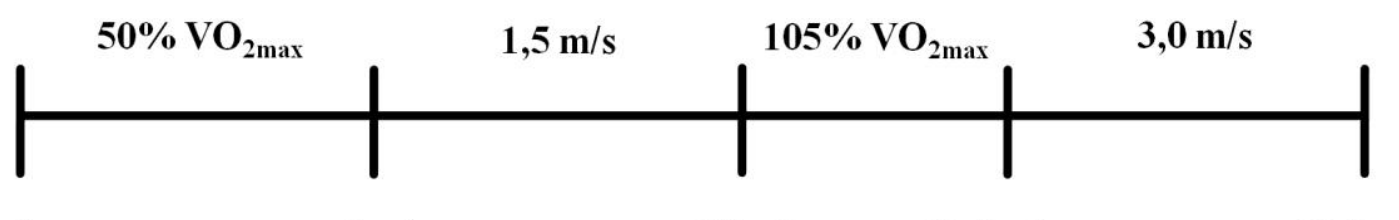

$\mathbf{0}$ $5 \mathrm{~min}$

10 min

$11,5 \mathrm{~min}$

$16,5 \mathrm{~min}$

Figura 1. Protocolo de exercício do teste de rápida aceleração e curta duração (TRA). 
A suplementação da vitamina $\mathrm{E}$ (dl-alfatocoferol) dos animais teve início logo após o TRA1, na dose de $1.000 \mathrm{UI} /$ animal, por meio de cápsulas gelatinosas (E-tabs 1000 UI, Sigma Pharma, Brasil) misturadas a raspas de rapadura, por via oral, diariamente, por 52 dias, sem interrupção até o final do experimento. Após o período da suplementação, os equinos realizaram o segundo teste (TRA2) com o mesmo protocolo de TRA1.

As colheitas de sangue foram realizadas nos momentos M0 (antes do exercício), PE (imediatamente após) e 1h, 3h, 6h, 12h e $24 \mathrm{~h}$ após o término do teste, em tubos contendo ativador da coagulação e tubos com EDTA potássico. $\mathrm{O}$ soro $\mathrm{e}$ o plasma foram imediatamente separados e congelados à temperatura de $-80^{\circ} \mathrm{C}$ até serem processados.

A avaliação de lipoperoxidação foi realizada por meio da determinação de malondialdeído (MDA) plasmático, por cromatografia líquida de alta eficiência (HPLC, Shimadzu Corp., Japão), segundo Nielsen et al. (1997). O perfil dos marcadores cardíacos foi realizado pelas determinações séricas de troponina I cardíaca, CK-MB e mioglobina por meio de kit comercial (Immulite, Siemens Medical Solutions Diagnostics, EUA), pelo ensaio imunoenzimático de fase sólida por quimioluminescência.

Realizou-se a análise estatística, inicialmente pela análise descritiva das variáveis e a comparação entre os momentos e provas pela análise de variância, com posterior teste de múltipla amplitude de Tukey em caso de distribuição paramétrica ou teste de KruskallWallis em caso de distribuição não paramétrica dos dados. A correlação entre os marcadores cardíacos foi realizada por meio de teste de correlação dos postos de Spearman. Todas as análises foram consideradas significativas quando $\mathrm{P}<0,05$.

\section{RESULTADOS}

Considerando as raças de equinos utilizadas, não houve diferença estatística entre as variáveis e, assim, os dados estão apresentados em conjunto. As concentrações plasmáticas de MDA não se alteraram estatisticamente com o exercício em ambas as provas, embora haja um discreto aumento imediatamente após o exercício, retornando ao nível basal em $1 \mathrm{~h}$. Com relação ao efeito da suplementação com vitamina $\mathrm{E}$, em todos os momentos, observaram-se valores menores de MDA após a suplementação (TRA2), porém houve diferença significativa somente no momento 24h $(\mathrm{P}<0,03)$ (Tab. 1).

O exercício causou um aumento discreto na concentração de cTnI sérica, sendo observado o valor máximo de $0,09 \mathrm{ng} / \mathrm{mL}$ em $6 \mathrm{~h}$ em TRA1, mas sem diferença estatística. Nesse momento, observou-se menor valor $(\mathrm{P}<0,05)$ após a suplementação (TRA2) quando comparado ao TRA1. Observou-se também, exceto pelos momentos $\mathrm{M} 0$ e 1h, menores níveis da cTnI após a suplementação em todos os momentos, entretanto sem diferença estatística (Tab. 1, Fig. 2).

O exercício provocou ainda elevação significativa $(\mathrm{P}<0,03)$ da concentração de CKMB em TRA1, em 12h. Em TRA2 também houve aumento da isoenzima, porém mais discreto e não significativo. Com exceção do M0, a concentração de CK-MB em todos os momentos foi menor em TRA2 em relação a TRA1, porém sem significância (Tab. 1). A concentração de mioglobina apresentou uma pequena elevação com valor máximo em $12 \mathrm{~h}$ após o exercício, em ambas as provas, porém não houve diferença estatística. Tampouco houve diferença nos momentos pré- e póssuplementação (Tab. 1).

Quanto à correlação dos marcadores cardíacos, a cTnI e a CK-MB apresentaram uma correlação significativa $(\mathrm{r}=0,60 ; \mathrm{p}=0,000)$. Porém, a correlação foi considerada muito baixa entre a CK-MB e a mioglobina $(r=0,22 ; p=0,009)$ e não houve entre cTnI e mioglobina $(r=0,14$; $\mathrm{p}=0,099$ ). 
Tabela 1. Médias ( \pm desvios-padrão) de malondialdeído $(\mu \mathrm{mol} / \mathrm{L})$ e de mioglobina $(\mathrm{ng} / \mathrm{mL})$ e medianas (percentil 25; percentil 75) de troponina I cardíaca $(\mathrm{ng} / \mathrm{mL})$ e CK-MB $(\mathrm{ng} / \mathrm{mL})$ de 10 equinos no teste de rápida aceleração e curta duração (TRA) antes (1) e após a suplementação com vitamina E (2)

\begin{tabular}{|c|c|c|c|c|c|c|c|c|c|}
\hline & \multicolumn{9}{|c|}{ Momentos } \\
\hline & & M0 & $\mathrm{PE}$ & $1 \mathrm{~h}$ & $3 \mathrm{~h}$ & $6 \mathrm{~h}$ & $12 \mathrm{~h}$ & $24 \mathrm{~h}$ & $p$ \\
\hline \multirow{5}{*}{ MDA } & \multirow{2}{*}{ TRA 1} & 1,38 & 1,54 & 1,21 & 1,39 & 1,21 & 1,16 & $1,26^{\mathrm{A}}$ & \multirow{2}{*}{0,354} \\
\hline & & $( \pm 0,35)$ & $( \pm 0,38)$ & $( \pm 0,29)$ & $( \pm 0,45)$ & $( \pm 0,54)$ & $( \pm 0,47)$ & $( \pm 0,25)$ & \\
\hline & \multirow{2}{*}{ TRA 2} & 1,06 & 1,32 & 1,06 & 1,23 & 1,16 & 1,04 & \multirow{2}{*}{$\begin{array}{c}0,83^{\mathrm{B}} \\
( \pm 0,49)\end{array}$} & \multirow{2}{*}{0,360} \\
\hline & & $( \pm 0,34)$ & $( \pm 0,59)$ & $( \pm 0,49)$ & $( \pm 0,48)$ & $( \pm 0,47)$ & $( \pm 0,37)$ & & \\
\hline & $\mathrm{p}$ & 0,053 & 0,333 & 0,430 & 0,449 & 0,847 & 0,536 & 0,023 & \\
\hline \multirow{7}{*}{ cTnI } & & 0,04 & 0,07 & 0,04 & 0,06 & $0,09^{\mathrm{A}}$ & 0,07 & 0,07 & \multirow{3}{*}{0,085} \\
\hline & TRA 1 & $(0,03$ & $(0,05$ & $(0,03$ & $(0,04$ & $(0,06$ & $(0,03$ & $(0,03$ & \\
\hline & & $0,05)$ & $0,11)$ & $0,05)$ & $0,14)$ & $0,26)$ & $0,12)$ & $0,10)$ & \\
\hline & \multirow{3}{*}{ TRA 2} & 0,05 & 0,04 & 0,04 & 0,05 & $0,05^{\mathrm{B}}$ & 0,04 & 0,03 & \multirow{3}{*}{0,437} \\
\hline & & $(0,01$ & $(0,04$ & $(0,02$ & $(0,03$ & $(0,03$ & $(0,03$ & $(0,02$ & \\
\hline & & $0,06)$ & $0,05)$ & $0,05)$ & $0,09)$ & $0,05)$ & $0,15)$ & $0,04)$ & \\
\hline & $\mathrm{p}$ & 0,817 & 0,127 & 0,291 & 0,849 & 0,048 & 0,909 & 0,052 & \multirow{4}{*}{0,024} \\
\hline \multirow{7}{*}{$\begin{array}{l}\text { CK- } \\
\text { MB }\end{array}$} & & $4,55^{\mathrm{a}}$ & $7,40^{\mathrm{ab}}$ & $5,55^{\mathrm{ab}}$ & $7,8^{\mathrm{ab}}$ & $9,35^{\mathrm{ab}}$ & $10,65^{\mathrm{b}}$ & $8,70^{\mathrm{ab}}$ & \\
\hline & TRA 1 & $(3,80$ & $(5,50$ & $(4,38$ & $(6,05$ & $(5,68$ & $(6,53$ & $(5,38$ & \\
\hline & & $6,50)$ & $10,55)$ & $7,68)$ & $10,40)$ & $12,10)$ & $13,13)$ & $10,38)$ & \\
\hline & \multirow{3}{*}{ TRA 2} & 5,10 & 5,75 & 4,75 & 6,65 & 7,05 & 7,00 & 5,45 & \multirow{3}{*}{0,089} \\
\hline & & $(3,90$ & $(4,63$ & $(4,48$ & $(5,55$ & $(5,45$ & $(5,00$ & $(4,60$ & \\
\hline & & $6,55)$ & $7,80)$ & $4,95)$ & $8,63)$ & $8,50)$ & $10,00)$ & $6,53)$ & \\
\hline & $\mathrm{p}$ & 0,596 & 0,307 & 0,325 & 0,376 & 0,384 & 0,364 & 0,056 & \\
\hline \multirow{5}{*}{ MIO } & TRA 1 & 0,26 & 0,28 & 0,28 & 0,27 & 0,32 & 0,36 & 0,27 & 0,149 \\
\hline & & $( \pm 0,07)$ & $( \pm 0,08)$ & $( \pm 0,07)$ & $( \pm 0,04)$ & $( \pm 0,11)$ & $( \pm 0,15)$ & $( \pm 0,09)$ & \\
\hline & & 0,30 & 0,25 & 0,29 & 0,26 & 0,30 & 0,33 & 0,31 & \multirow{2}{*}{0,334} \\
\hline & 1RA 2 & $( \pm 0,10)$ & $( \pm 0,04)$ & $( \pm 0,09)$ & $( \pm 0,08)$ & $( \pm 0,07)$ & $( \pm 0,06)$ & $( \pm 0,11)$ & \\
\hline & $\mathrm{p}$ & 0,212 & 0,331 & 0,844 & 0,689 & 0,597 & 0,546 & 0,211 & \\
\hline
\end{tabular}

M0: antes do exercício, PE: imediatamente após o exercício, MDA: malondialdeído, cTnI: troponina I cardíaca, CKMB: isoenzima MB da creatinoquinase, MIO: mioglobina.

Letras minúsculas na mesma linha indicam diferença estatística entre momentos.

Letras maiúsculas na mesma coluna indicam diferença estatística entre provas. 


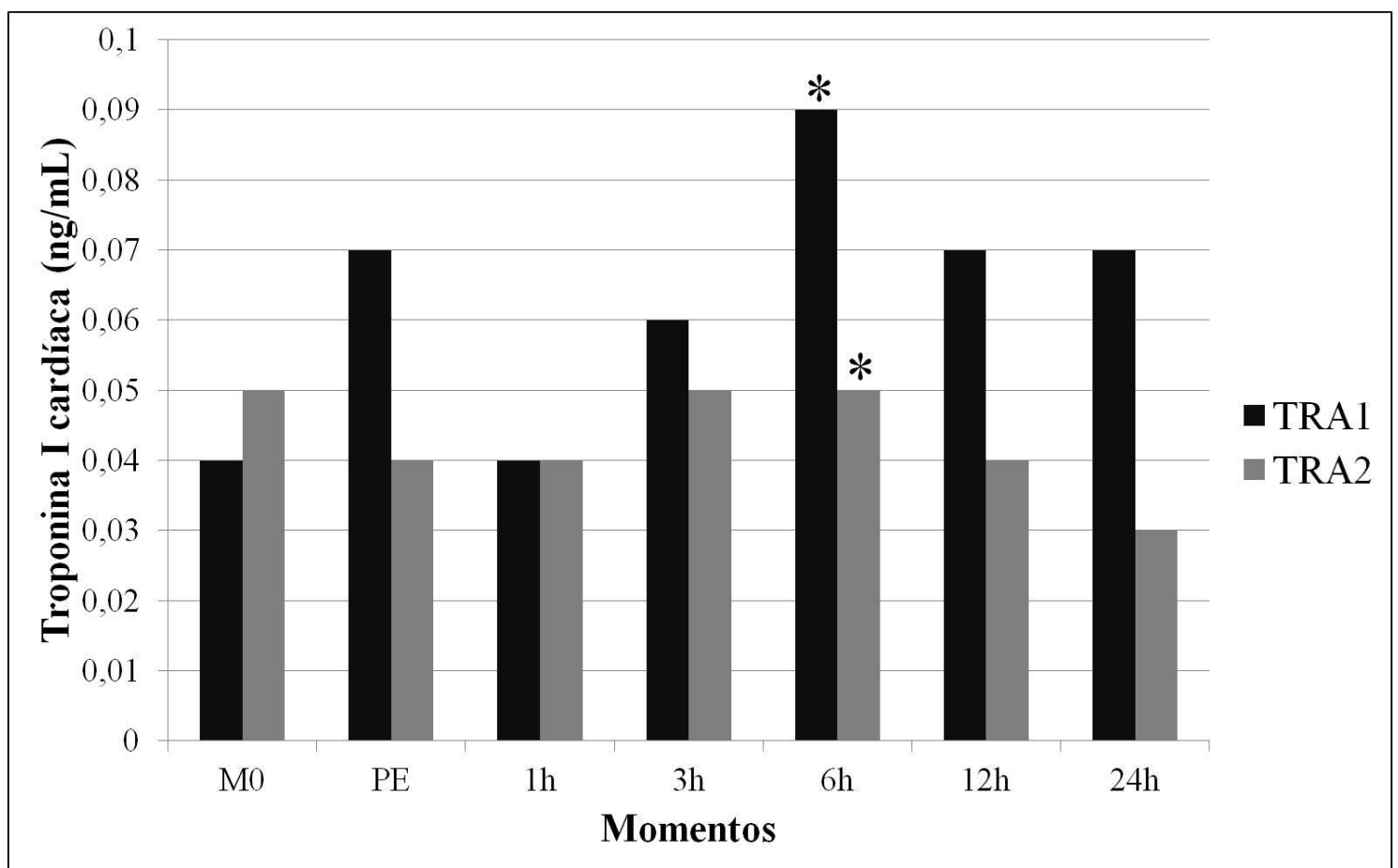

Figura 2. Medianas da concentração de troponina I cardíaca $(\mathrm{ng} / \mathrm{mL})$ de 10 equinos submetidos ao teste de rápida aceleração e curta duração (TRA) antes (1) e após a suplementação com vitamina E (2). *Diferença estatística entre provas $(\mathrm{P}<0,05$, Kruskall-Wallis $)$.

\section{DISCUSSÃO}

Os marcadores de lipoperoxidação e a vitamina E são os mais extensivamente estudados quanto à formação e redução do estresse oxidativo, respectivamente, induzido pelo exercício físico (Deaton e Martin, 2003; Williams, 2010). Entretanto, há uma ampla variação de resultados e não foram estabelecidos ainda os benefícios reais da utilização desse antioxidante (Duberstein et al., 2009; Yonezawa et al., 2010a). Sugere-se que a inconsistência desses resultados possa ser atribuída a diferentes intensidades de exercício, duração, tipo ou treinamento, ou método usado para averiguar a lipoperoxidação.

As concentrações de MDA de repouso pré- e pós-suplementação foram superiores às encontradas por Yonezawa et al. (2010a) em equinos submetidos a exercício progressivo, sendo $1,07 \pm 0,67 \mu \mathrm{mol} / \mathrm{L}$ para o grupo controle e $0,66 \pm 0,51 \mu \mathrm{mol} / \mathrm{L}$ para o grupo suplementado com vitamina E na mesma dose de 1.000 UI por dia. Houve uma clara tendência do exercício de alta intensidade em provocar maior produção de ERO evidenciada pela elevação dos níveis de MDA em ambas as provas, em acordo com os dados da literatura (Avellini et al., 1999; Yonezawa et al., 2010a). Duberstein et al. (2009) submeteram equinos a treinamento e suplementação com vitamina $\mathrm{E}$ na dose de 3.000UI por dia e, no final do treinamento, realizaram teste de exercício progressivo. Os autores encontraram uma concentração pósexercício menor de substâncias reativas ao ácido tiobarbitúrico, que incluem o MDA, em relação ao pré-exercício, provavelmente devido à rápida depuração do MDA, uma vez que apresenta meia-vida curta. Sugere-se que, no presente estudo, o protocolo de exercício não foi intenso o suficiente para provocar estresse oxidativo. Outro fator que possivelmente pode ter contribuído para os baixos valores de MDA seria o bom condicionamento físico dos animais, embora não fossem treinados. Sabe-se que os cavalos são atletas natos e, quando são alimentados com uma dieta de boa qualidade, apresentam as defesas antioxidantes endógenas adequadas para uma rápida depuração de ERO do organismo.

A suplementação foi benéfica ao amenizar a produção de ERO, sendo verificada pelos menores valores plasmáticos de MDA em todos 
os momentos de TRA2 em relação ao TRA1, porém houve diferença estatística somente em 24h. No estudo de Avellini et al. (1999), houve aumento significativo das defesas antioxidantes, que reduziu o fenômeno peroxidativo induzido pelo exercício de alta intensidade ao associar um período de treinamento com a suplementação de selênio e vitamina E por 70 dias. Entretanto, Yonezawa et al. (2010a) observaram maior produção de MDA pelo grupo suplementado com vitamina $\mathrm{E}$ em relação ao grupo controle de equinos submetidos a exercício progressivo, possivelmente em decorrência do efeito pró-oxidante da vitamina E. Williams e Carlucci (2006) não encontraram diferenças nos parâmetros de estresse oxidativo ao suplementarem equinos de trote com $0,5.000 \mathrm{e}$ 10.000UI de acetato de dl-alfa-tocoferol por três semanas e submeterem a exercício intenso. Os autores ainda recomendam que a dose de 10.000UI deve ser evitada pois pode ser prejudicial à absorção de betacaroteno.

Segundo van Erck et al. (2008), a disfunção cardíaca está associada a altos níveis de marcadores de estresse oxidativo. No presente estudo, não foi possível correlacionar os valores de MDA com os de cTnI. Observou-se leve aumento da concentração de cTnI no TRA1 em 6 h $(0,09 \mathrm{ng} / \mathrm{mL})$ acima do limite da variação considerada normal proposta por Divers et al. (2010) em 83 cavalos, de 0,0 a $0,06 \mathrm{ng} / \mathrm{mL}$, indicando que o protocolo de exercício causou um leve grau de estresse miocárdico, porém pouco expressivo. Em acordo, Durando et al. (2007) verificaram aumento discreto dos níveis de cTnI em equinos submetidos a exercício máximo de curta duração, assim como Nostell e Häggström (2008) e Yonezawa et al. (2010), que ainda associaram a elevação à ocorrência de contrações ventriculares prematuras.

Ainda que existam na literatura muitos trabalhos que relatam elevação da concentração sérica de troponina após atividade física, não há um consenso sobre a prevalência, os mecanismos e o significado clínico da liberação de troponina induzida pelo exercício, existindo várias hipóteses. Uma delas é o aumento da permeabilidade sarcolemal do miocárdio que pode facilitar a liberação da cTnI citosólica. Assim, é possível que a elevação da troponina pós-exercício ocorra devido à difusão passiva do compartimento intra para o extracelular.
Esse aumento da permeabilidade pode ser ocasionado por mecanismos de estresse sobre os cardiomiócitos, produção elevada de ERO ou desequilíbrio ácido-base (Shave et al., 2010). O exercício físico extremo pode ainda levar a aumentos da troponina, não só pelo maior consumo do oxigênio por parte do miocárdio, como também por uma potencial diminuição da perfusão coronariana por vasoespasmo induzido pelas catecolaminas endógenas. Outro mecanismo de liberação de troponina induzida pelo exercício é a estimulação de integrinas por meio do estiramento do miocárdio. As integrinas agem como moléculas sinalizadoras e estão envolvidas no remodelamento cardíaco por sobrecarga de pressão ou após infarto do miocárdio. A estimulação das integrinas responsivas ao estiramento medeia o transporte de moléculas intactas de troponina para fora dos cardiomiócitos. Como a maioria dos dados da literatura envolve indivíduos saudáveis, especula-se que a liberação pós-exercício da cTnI seja um processo benigno e que não está relacionada com necrose miocárdica (Martins, 2009; Shave et al., 2010). Contudo, não há dados que estimam se essa liberação transitória esteja relacionada a alterações cardíacas futuras.

Outro fator importante a ser considerado com relação às divergências dos dados na literatura são os diferentes sistemas analisadores que utilizam aminoácidos distintos para composição dos anticorpos monoclonais. A dificuldade em comparar os dados com os apresentados na literatura se deve a essa divergência de metodologias e tipos de amostragem (Yonezawa et al., 2010a; Durando et al., 2007). Sabe-se que a troponina I é liberada para a circulação sob três formas: livre (cTnI) ou em complexo com as outras troponinas C e T (cTnI-C e cTnI-T-C), podendo apresentar diferentes graus de degradação (Yonezawa et al., 2010b). Devido à variação da presença dessas formas, é altamente desejável que o imunoensaio seja capaz de detectar e quantificar as três (Oyama e Solter, 2004). Adicionalmente, Katrukha et al. (1997) relataram que as regiões amino- e carboxiterminal da cTnI são vulneráveis à degradação. Shi et al. (1999) demonstraram que a região aminoterminal parece ser mais estável que a carboxiterminal. Desse modo, esses achados são importantes para explicar a ampla variação dos valores mensurados por diferentes ensaios de cTnI (Yonezawa et al., 2010b). 
Assim, há necessidade de um estudo amplo comparando os diversos tipos de kits analisadores comerciais para determinação da cTnI na espécie equina, como já realizado para humanos, ratos, cães e macacos (Panteghini et al., 2004; Apple et al., 2008).

Mesmo que o exercício não tenha promovido grandes alterações nos níveis de cTnI, a suplementação com vitamina $\mathrm{E}$ proporcionou efeito protetor no coração, evidenciado pela menor liberação de troponina no momento $6 \mathrm{~h}$ de TRA2 em relação a TRA1. Este é o primeiro relato desse efeito benéfico da vitamina E sobre o miocárdio de equinos.

Michima et al. (2010) acreditam que a utilização da CK-MB como único marcador cardíaco não traz informações relevantes a respeito da integridade cardíaca sob influência do exercício. No presente estudo verificou-se aumento significativo da isoenzima em $12 \mathrm{~h}$ no TRA1, acompanhado por uma correlação significativa com a cTnI. Os dados sugerem que, quando associada à troponina I cardíaca, a CK-MB pode aumentar sua especificidade na detecção de alteração miocárdica. Observou-se também uma tendência do mesmo efeito protetor da vitamina E sobre o miocárdio evidenciado pelos menores níveis de CK-MB no TRA2 em relação ao TRA1, todavia sem significância. Para uma melhor compreensão dos mecanismos de liberação dos marcadores cardíacos induzidos pelo exercício, são necessários novos estudos, principalmente que considerem os diferentes tipos de analisadores na espécie equina.

Quanto à concentração de mioglobina, as alterações ocasionadas pelo exercício e pela suplementação foram muito sutis. A partir desses dados e por existir uma correlação muito baixa com a cTnI e CK-MB, não se recomenda a utilização desse marcador para avaliação miocárdica em equinos submetidos a exercício de alta intensidade. Talvez essa proteína seja mais útil na avaliação da musculatura esquelética (Holmgren e Valberg, 1992).

\section{CONCLUSÕES}

Concluiu-se que o exercício de rápida aceleração e curta duração, considerado de alta intensidade, induziu estresse miocárdico em equinos evidenciado pelo aumento de CK-MB, mas não foi considerado grave. Pelos dados do presente trabalho, ainda foi possível verificar o efeito benéfico da suplementação da vitamina $\mathrm{E}$ pela diminuição da concentração de MDA plasmático e de cTnI sérica.

\section{AGRADECIMENTOS}

Os autores agradecem à Fundação de Amparo à Pesquisa do Estado de São Paulo (FAPESP) pelo subsídio financeiro para a realização deste estudo.

\section{REFERÊNCIAS}

APPLE, F.S.; MURAKAMI, M.M.; LER, R. et al. Analytical characteristics of commercial cardiac troponin I and $\mathrm{T}$ immunoassays in serum from rats, dogs, and monkeys with induced acute myocardial injury. Clin. Chem.,v.54, p.1982-1989, 2008.

ASCENSÃO, A.; MAGALHÃES, J.; SOARES, J. et al. Exercício e stress oxidativo cardíaco. Rev. Port. Cardiol., v.22, p.651-678, 2003.

AVELLINI, L.; CHIARADIA, E.; GAITI, A. Effect of exercise training, selenium and vitamin $\mathrm{E}$ on some free radical scavengers in horses (Equus caballus). Comp. Biochem. Physiol. B, v.123, p.147-154, 1999.

CERQUEIRA, F.M.; MEDEIROS, M.H.G.; AUGUSTO, O. Antioxidantes dietéticos: controvérsias e perspectivas. Química Nova, v.30, p.441-449, 2007.

DEATON, C.M.; MARLIN, D.J. Exercise-associated oxidative stress. Clin. Tech. Equine Pract., v.2, p.278291, 2003.

DIVERS, T.J.; KRAUS, M.S.; RADCLIFFE, R.M. et al. Measurement and clinical use of cardiac troponin I (cTnI) in horses. In: ANNUAL CONVENTION OF THE AMERICAN ASSOCIATION OF EQUINE PRACTITIONERS, 56., 2010, Baltimore. Proceedings... Baltimore: [s.n.] 2010. p.277-278 Disponível em: <http://www.ivis.org/proceedings/ aaeP>. Acessado em 07 jan. 2011.

DUBERSTEIN, K.J.; JOHNSON, S.E.; MCDOWELL, L.R. et al. Effects of vitamin E supplementation and training on oxidative stress parameters measured in exercising horses. Comp. Exerc. Physiol., v.6, p.17-25, 2009.

DURANDO, M.M.; REEF, V.B.; KLINE, K. et al. Acute effects of short duration, maximal exercise on cardiac troponin I in healthy horses. Equine Comp. Exerc. Physiol., v.3, p.217-223, 2007. 
GODOY, M.F.; BRAILE, D.M.; PURINI NETO, J. A troponina como marcador de injúria celular miocárdica. Arq. Bras. Cardiol.,v.71, p.629-633, 1998.

HOLMGREN, N.; VALBERG, S. Measurement of serum myoglobin concentrations in horses by immunodiffusion. Am. J. Vet. Res., v.53, p.957-960, 1992.

KATRUKHA, A.G.; BEREZNIKOVA, A.V.; ESAKOVA, T.V. et al. Troponin I is released in bloodstream of patients with acute myocardial infarction not in free form but

as a complex. Clin. Chem., v.43, p.1379-1385, 1997.

KOSTAROPOULOS, I.A.; NIKOLAIDIS, M.G.; JAMURTAS, A.Z. et al. Comparison of the blood redox status between long-distance and short-distance runners. Physiol Res., v.55, p.611-616, 2006.

MARTINS, C.S. Troponina. Estrutura, fisiopatologia e importância clínica para além da isquemia miocárdica. Arq. Med., v.23, p.221-240, 2009.

MICHIMA, L.E.S.; MIRANDOLA, R.M.S.; FERNANDES, W.R. Estudo da isoenzima creatina quinase CKMB sérica em equinos de enduro após exercício físico prolongado. Braz. J. Vet. Res. Anim. Sci., v.47, p.23-20, 2010.

NIELSEN, F.; MIKKELSEN, B.B.; NIELSEN, J.B. et al. Plasma malondialdehyde as biomarker for oxidative stress: reference interval and effects of lifestyle factors. Clin. Chem., v.43, p.1209-1214, 1997.

NOSTELL, K.; HÄGGSTRÖM, J. Resting concentrations of cardiac troponin I in fit horses and effect of racing. J. Vet. Cardiol., v.10, p.105-109, 2008.

OYAMA, M.A.; SOLTER, P.F. Validation of an immunoassay for measurement of canine cardiac troponin-I. J. Vet. Cardiol., v.6, p.17-24, 2004.

PANTEGHINI, M.; PAGANI, F.; YEO, K.T.J. et al. Evaluation of imprecision for cardiac troponin assays at low-range concentrations. Clin. Chem., v.50, p.327332, 2004.

PHILLIPS, W.; GIGUÈRE, S.; FRANKLIN, R.P. et al. Cardiac troponin I in pastured and race-training Thoroughbred horses. J. Vet. Intern. Med., v.17, p.597-599, 2003.
PRINCE, A.; GEOR, R.; HARRIS, P. et al. Comparison of the metabolic responses of trained Arabians and Thoroughbreds during high- and lowintensity exercise. Equine Vet J., v.34, p.95-99, 2002.

REIMER, J.M.; REEF, V.B.; SWEENEY, R.W. Ventricular arrhythmias in horses: 21 cases (19841989). J. Am. Vet. Med. Assoc., v.201, p.1237-1243, 1992.

SHAVE, R.; BAGGISH, A.; GEORGE, K. et al. Exercise-induced cardiac troponin elevation. J. Am. Coll. Cardiol., v.56, p.169-176, 2010.

SHI, Q.; LING, M.; ZHANG, X. et al. Degradation of cardiac troponin in serum complicates comparisons of cardiac troponin I assays. Clin. Chem., v.45, p.10181025, 1999.

VAN ERCK, E.; LOIGEROT, C.; LEKEUX, P. et al. Oxidative stress and clinical status in working Standardbred horses. In: BRITISH EQUINE VETERINARY ASSOCIATION CONGRESS, 47., 2008., Liverpool. Proceedings... Liverpool: [s.n.] 2008. p.344. Disponível em: <http://www.ivis.org/ proceedings/beva/2008/part4.pdf\#nameddest=8>. Acessado em: 07 jan. 2010.

WATANABE, M.J.; SILVEIRA, V.F.; MACHADO, L.P. et al. Aplicação da espirometria durante teste padrão de exercício progressivo em esteira para avaliação da troca gasosa respiratória de equinos da raça Árabe. Arch. Vet. Sci., v.14, p.17-24, 2009.

WILLIAMS, C.A. Antioxidant supplementation to the exercising horse. Rev. Bras. Zootec., v.39, p.145-150, 2010.

WILLIAMS, C.A.; CARLUCCI, S.A. Oral vitamin E supplementation on oxidative stress, vitamin $\mathrm{E}$ and antioxidant status in intensely exercised horses. Equine Vet. J., v.36, p.617-621, 2006.

YONEZAWA, L.A.; MACHADO, L.P.; SILVEIRA, V.F. et al. Malondialdeído e troponina I cardíaca em equinos da raça Puro Sangue Árabe submetidos ao exercício e à suplementação com vitamina E. Rev. Cienc. Rural, v.40, p.1321-1326, 2010a.

YONEZAWA, L.A.; SILVEIRA, V.F.; MACHADO, L.P. et al. Marcadores cardíacos na medicina veterinária. Rev. Cienc. Rural, v.40, p.222-230, 2010 b. 